\title{
A criação do personagem cinebiográfico para o cinema: os desafios do roteirista para criar ou recriar
}

\author{
Francisco Malta \\ Universidade Estácio de Sá, Brasil
}

\begin{abstract}
The proposal is a research update where part of this research is to discuss the care to the writer needs to have in re-creating characters for a biopic in the construction of a screenplay. As a corpus, we will work with the writer Machado de Assis, who will guide us as a character in a writing proposal for his biopic. What are the main challenges of the writer: choosing a single biographical cut or keeping true to the facts? do we need to use poetic license? These are some of the questions that we intend to address, as well as the production adjustments for the realization of an audiovisual product.
\end{abstract}

Keywords: Script, Cinema, Creation, Biographical, Machado de Assis

\section{Introdução}

Contar uma história é um dos princípios da condição humana. Recontar uma história é outra parte deste princípio. O reconstruir permite enxergar no espelho do outro e assim trazer para si a reflexão. A escolha de reconstruir para as telas a história de um personagem da vida real implica em muitas decisões por parte do roteirista. Suas escolhas recaem sobre o recorte estabelecido e o direcionamento da história. Embora a criação para o audiovisual seja um trabalho de equipe em seu resultado final, o guia de toda produção se estabelece na elaboração do roteiro, onde cabe ao roteirista a pesquisa cuidadosa e a responsabilidade da recriação da história ao que tange as cinebiografias.

A proposta da construção narrativa no roteiro cinematográfico surge de uma ideia que posteriormente será transformada em argumento e este por sua vez receberá o tratamento com seus diálogos, personagens e implicações desta gramática audiovisual. Este viés de edificação atende a uma necessidade da história e aos elementos que precisamos para compor o universo imagético. Dentro desta proposta encontra-se o trabalho da pesquisa, um dos pilares fundamentais para essa realização. Este artigo pretende discutir o suporte da pesquisa em torno de um personagem real como sustentação para construção do roteiro. Até onde podemos ser fiel ao personagem e até que ponto podemos usar a liberdade criativa para contar tal história? O corpus vai partir de uma experiência pessoal como roteirista e os desafios no processo de criação desta escrita. O trabalho se destina a escrever um roteiro de longametragem sobre a vida do escritor Machado de Assis.

Para o desenvolvimento deste projeto o primeiro passo é a pesquisa, principalmente por se tratar de um homem que traz uma representatividade bem forte para os brasileiros. O nome Machado de Assis refere-se a um dos mais expressivos autores da Língua portuguesa. Fundador da Academia Brasileira de Letras, tornou-se também um personagem que desperta a curiosidade sobre sua vida e obra. Decifrar o homem Machado exige uma pesquisa minuciosa do contexto de uma época e seus desdobramentos. A maestria de sua escrita abre caminhos para um debate em torno da lenda em que se tornou o próprio autor: um personagem complexo e cheio de camadas.

O processo do ato de criação pressupõe uma linha tênue entre criador e criatura, o que às vezes se confunde e torna-se lugar comum buscar um entendimento da vida do autor pelo viés dos personagens escritos. Machado de Assis é a referência máxima da literatura brasileira, onde construiu tramas que estão ligadas a todos os arquétipos universais. $\mathrm{O}$ autor teve o merecido reconhecimento em vida e já ganhou inúmeras análises de suas obras, assim como diferentes biografias. As construções literárias em Machado de Assis apostam em temas, e não de uma forma simplista. Mais do que isso, a linha narrativa alcança um outro patamar, diferenciando-o de seus contemporâneos.

Ao trabalhar em uma cinebiografia, o roteirista se vê diante de uma bastante situação sensível: ser fiel ao personagem ou escolher um recorte? São muitos os exemplos de cinebiografia bem-sucedidas e outras fracassadas na história do cinema. Tal escolha refletirá diretamente no processo da produção podendo ou não alcançar sucesso de público e crítica. Críticas como a não fidelidade aos fatos são as mais comuns, porém, a defesa neste caso é bastante clara, pois o roteirista está fazendo um roteiro de ficção e não um documentário e só por este fato já o difere de ater a quaisquer esclarecimentos. Pensar o recorte é o maior dos desafios, não somente pelo que o roteirista pretende aplicar no desenrolar das tramas, mas acima de tudo não deixar se levar pelo caminho mais fácil no processo de escrita e criação.

\section{O personagem}

O cinema e a televisão há anos deram vozes a cinebiografia de escritores conhecidos do grande público, alguns tornaram- se sucesso de público e crítica e outros passaram longe de qualquer apelo emocional. A título de registro no âmbito internacional podemos citar Piaf: um hino de amor (2007), com roteiro e direção de Olivier Dahan, e A teoria de tudo (2017), que traz para as telas a vida do físico Stephen Hawking, com roteiro de Anthony Mccarten e direção de James Marsh. No Brasil, temos cinebiografias memoráveis escritas para cinema e Televisão. No cinema, temos Mauá: o imperador e o Rei, de Sergio Resende (1999), o filme conta a infância, o enriquecimento e falência do Barão de Mauá, considerado o primeiro grande empresário brasileiro. 
Em 2004, tivemos Cazuza o tempo não para, de Sandra Werneck, sobre o cantor e compositor Cazuza. $\mathrm{Na}$ TV já tivemos de JK, de Maria Adelaide Amaral (2006) a Maysa, de Manoel Carlos, em 2008.

Quando o escritor tem uma ideia para o desenvolvimento de uma história, seja para o cinema, televisão, teatro ou literatura, o mesmo rascunha personagens e temas para assim construir o seu roteiro. Para o desenvolvimento do argumento inicial, o contexto da história ou do personagem, vai necessitar de uma pesquisa. Naturalmente que nem todos trabalham dentro desse procedimento, assim como nem todos os roteiros necessitam de uma pesquisa prévia, pois a pesquisa atende a uma necessidade de suporte para a história.

$\mathrm{O}$ caso específico de um personagem biografado e conhecido do grande público vai exigir do roteirista não somente um cuidado maior com a pesquisa, mas também com o recorte. Afinal, se todos conhecem o personagem, as expectativas serão grandes, isso para o bem ou para o mal.

O conceito de Mise em scéne, trabalhado por Tarkovski, nos auxilia neste quesito na elaboração das cenas, por exemplo. Para Tarkovski, "seu objetivo não deve reduzir-se a uma elaboração do significado de um diálogo ou de uma sequência de cenas." (TARKOVSKI, 1990, p.23). Em acordo com o autor, o roteirista também não deve escrever uma cena apenas para atender uma sequência. É preciso perceber a necessidade da cena ou do diálogo, afinal, a escrita cinematográfica preza pelas imagens e pelo arco narrativo. O mesmo acrescenta que "o que torna a cena tão irrestível quanto a própria vida é a recusa em sobrecarregar a cena com ideias óbvias." (TARKOVSKI, 1990, p. 25). Essa percepção podemos ter pela escaleta. Em um roteiro cinematográfico, uma das ferramentas que auxilia o roteirista é a escaleta, onde o mesmo pode visualizar as cenas antes do processo de escrita do roteiro propriamente dito. Por escaleta, entende-se que "é a descrição resumida das cenas de um roteiro, na sua sequência." (CAMPOS, 2007, p. 305). O lugar onde você coloca as cenas já sugere as ações e o arco narrativo dos personagens, assim como é possível definir claramente os pontos de virada na trama. Ou seja, antes do processo de desenvolvimento do roteiro em si já podemos visualizar os pontos de viradas e arcos narrativos, tanto em relação ao desenrolar do personagem, como em relação a história.

\section{A pesquisa como suporte para elaboração do roteiro}

Machado de Assis, um dos mais célebres escritores da literatura brasileira, nunca esteve como personagem nas telas do nosso cinema. Como autor, muitas de suas histórias já ganharam vida nas telas do cinema e da TV, mas o homem Machado de Assis, o sujeito por trás de obras consagradas e personagens dúbios, ainda não foi retratado. Portanto, o momento é propício a levar para as telas a história deste homem que foi um exemplo de superação.

Uma vez escolhido um personagem a ser cinebiografado, começa a tarefa cuidadosa dos levantamentos de dados o qual podemos nos apoiar nas biografias já publicadas. No caso de Machado de Assis, são mais de dez biografias escolhidas e algumas com fontes não muito confiáveis. Um lado positivo dessa diversificação de leituras são os coloridos que podemos pegar de uma cada uma destas biografias e aplicar na construção das tramas.

Machado é um escritor multifacetado e dono absoluto do seu ofício. Um homem com profundo conhecimento de sua sociedade e país. Em sua escrita perpassa os questionamentos da natureza humana. A narrativa machadiana em nada preza o regionalismo e não há nenhum demérito nisso. É possível amarrar as pontas de um escritor do século XIX com um escritor do século XXI?

\section{Metodologia}

Para este trabalho, foi essencial a leitura das diferentes obras lançadas a respeito de Machado de Assis. Fez-se necessário elencar as principais biografias, assim como um fichamento de suas obras, documentários que já foram realizados a respeito do autor e respectivas obras, e ainda artigos sobre o autor publicados no exterior. Outros pontos que considero relevantes são as visitas na Academia Brasileira de Letras, assim como locais que eram frequentados pelo escritor, tais como o Real Gabinete Português e a Confeitaria Colombo. Também penso entrevistar professores especialistas em Machado de Assis e alguns escritores como: Silviano Santiago e João Cézar de Castro. Para além do roteiro, penso em entrevistar Maria Adelaide Amaral, roteirista responsável pela biografia de JK na TV Globo, e Maria Camargo, roteirista responsável pela série Dois Irmãos na TV Globo, adaptação do romance de Milton Hatoum.

\section{Primeira etapa da pesquisa: investigando a origem do personagem}

De origem humilde, o homem Machado de Assis nasceu no Morro da Providência, antigo Morro do Livramento, em 21 de junho de 1839, vindo a falecer em 29 de setembro de 1908, ou seja, à época em que viveu enfrentou um período de transição do próprio país. Tal período é elemento importante de ser observado, visto que essa contextualização política e econômica perpassa em sua obra, mas não de uma maneira didática, uma vez que sua escrita era muito sofisticada para a ocasião, assim como para seus colegas letrados. Durante seus 69 anos, muito do que viveu provocou repulsa em seus inimigos, nem sempre declarados.

Machado não teve uma formação como outros escritores. Seus estudos se deram de forma irregular. Não obstante, sua história de superação é digna de um personagem de folhetim, com todas as camadas e pontos de virada. Nasceu filho de uma lavadeira açoriana e um pintor mulato, órfão muito cedo foi criado pela madrasta, a qual abandonou tão logo tornou-se adolescente, em uma tentativa de romper com o passado, como esclareceu Lucia Miguel Pereira 
(1988), ainda fundou uma Academia de Letras e enfrentou questões como a escravidão e divisão de terras. São muitos os pontos que tornam Machado um personagem difícil em sua construção. Se o folhetim exige mais do que uma jornada para um herói seguir, o que dizer do homem que foi acusado de esquecer os negros, sendo ele um descendente, e que vivenciou um romance com uma mulher portuguesa de meia idade, tabu para os preceitos da época. Romance ou folhetim? Nem um e nem outro, os caminhos da arte também podem imitar os caminhos da vida neste personagem enigmático.

Para alguns estudiosos, como Lucia Miguel Pereira, a história de Machado se dá em uma linha vertical, no qual o mesmo possui um objetivo e quer se ascender socialmente. Em acordo com essa leitura de Lucia Miguel Pereira, e tendo o mesmo como um personagem de trajetória, a proposta do longa metragem é tratar dessas vertentes de modo a revelar ao público esse outro lado do autor. Para Vogler "toda boa história é um reflexo da história humana total, da condição humana universal de nascer neste mundo, crescer, aprender, lutar para se tornar um indivíduo, e morrer". (VOGLER, 2006, p.72).Ainda segundo Vogler, as histórias podem ser lidas como metáforas da condição humana geral, com personagens que incorporam qualidades universais arquetípicas, compreensíveis para o grupo, assim como para o indivíduo.

Essa origem humilde traz para o menino Machado a garra de vencer. Segundo Alfredo Bosi, "aprendidas as primeiras letras numa escola pública, recebeu aulas de francês e de latim de um padre amigo, Silveira Sarmento, mas foi como autodidata que construiu sua vasta cultura literária, que incluía autores como Sterne e Leopardi."(BOSI, 2006, p. 174). A pesquisa de Lucia Miguel Pereira acresce essa informação: "Através do forneiro há de ter penetrado na família de M. Gallot, pois, já velho contava que praticara francês na casa de uma família que frequentara assiduamente." (PEREIRA, 1988, p. 43). Já ciente e consciente da sua condição, Machado se emprega na editora de Paula Brito como tipógrafo, onde, por intermédio do mesmo, conheceu muita gente influente e publicou seu primeiro poema. Essa ligação, como observa Jean Michel Massa, se deu também pela origem e pela cor. "Francisco de Paula Brito, mulato saído de um meio bastante humilde de artesãos, era homem que se fizera por si mesmo. Aprendera o ofício de tipógrafo na Imprensa Nacional" (MASSA, 2008, p. 84). De certo nessas ocasiões, e pelo senso de observação que o acompanhava, ali já podia perceber nitidamente os papéis que cada indivíduo desempenhava na sociedade. O poder, o dinheiro, a influência política, são alguns dos elementos que podemos elencar nesta construção e, como já diz a própria escrita machadiana "hás de reconhecer que uma estava dentro da outra, como a fruta dentro da casca." (ASSIS, 2015, p.148). O Machado maduro já estava presente naquele adolescente visionário e sem nenhum recurso.

Machado foi um observador do modo de formação da sociedade brasileira. Em 1864, assume um cargo no Ministério da Agricultura, onde se incumbe de fiscalizar a aplicação da lei do ventre livre e a política de terras. Não há como negar que esta experiência influencia na maneira de representar as classes sociais em suas narrativas. Em Dom Casmurro temos a presença de José Dias, agregado da casa de Bentinho. Homem livre, mas sem posses, integra-se ao clã e acaba por perder sua identidade, mas o mantém próximo ao status social que o mesmo deseja participar.

Artisticamente captou como a sociedade criava mecanismos para manter ao longo do tempo as estratégias de exclusão e privilégios. Este pensamento também já aparecia em Esaú e Jacó: "o regime, sim, era possível, mas também se muda de roupa sem trocar de pele" (ASSIS, 2015, p. 85). Para João Almino, Machado "não acreditava cegamente no progresso. Não era socialista, republicano nem abolicionista. No entanto, todas essas correntes filosóficas, políticas e estéticas estão tratadas, à distância, em sua obra." (ALMINO, apud ROCHA, 2016,p. 272). Além da maestria com contos e romances, Machado foi um exímio tradutor. Ele trouxe a público obras de autores como: Shakespeare, Dickens e Edgar Allan Poe. Maria Aparecida Salgueiro destaca:

Ele estava absolutamente consciente da tensão
existente na tradução, ou em outras palavras, tinha
clareza que, ao mesmo tempo em que a tradução
pode atuar como veículo de modernização,
ela pode também agir como um obstáculo
ao desenvolvimento de talentos nacionais.
(SALGUEIRO, apud ROCHA, 2016, p. 299)

Uma questão que persegue a identidade do escritor é em relação a sua cor e origem. Segundo Salgueiro, "alguns críticos apontam que a barba e o cabelo rigorosamente escovados em sua fotografia poderiam ser uma tentativa de esconder seus traços africanos. Outros mencionam sua preferência por personagens da aristocracia" (SALGUEIRO, apud ROCHA, 2016, p. 300). Esse pensamento indica um possível complexo de inferioridade racial ou social. Machado acabou por criar um personagem de si mesmo, o que se depreende das fotos e depoimentos da época. Talvez pela postura e reserva pessoal, o mesmo acabou por se distanciar dessa sociedade aviltante que traz o preconceito velado. No entender de Alfredo Bosi:

\footnotetext{
Veio-lhe sempre do espírito atilado um não ao convencional, um não que o tempo foi sombreando de reservas, de mas, de talvez, embora permanecesse até o fim como espinha dorsal de sua relação com a existência. A gênese dessa posição, que vela as negações radicais com a linguagem da ambiguidade, interessa tanto ao sociólogo ao pesquisar os problemas da classe do mulato pobre que venceu a duras penas, como ao psicólogo para quem a gagueira, a epilepsia e a consequente timidez do escritor são fatores que marcaram primeiro o rebelde, depois o funcionário e o acadêmico de notória compostura. (BOSI, 2006,p. 176)
}

Outro fato de igual relevância são as leituras realizadas por Machado. Autor atento à boa leitura, era um conhecedor da obra de Shakespeare, o que 
podemos perceber em seus próprios textos, como em Dom Casmurro, na passagem que Bentinho e Capitu vão à ópera no Teatro Municipal e a encenação é Othelo. Se Shakespeare apropriou-se do que já existia para criar suas tramas e nasce também em um período sócio-político conturbado, a sua retórica vem da Grammar School, ao contrário de Machado que precisou se superar não somente para leis de sobrevivência, mas também como profissional das letras. Em acordo com Daniel Piza, não podemos "esquecer que a obra de Machado transcendeu sua época e não pode ser explicada mecanicamente por sua vida." (PIZA, apud, ROCHA, 2016, p. 202). Vale ressaltar que essa tentativa de explicar a vida pela obra não é sempre coerente com o autor, o que desprezaria o processo de criação em si.

\section{Autor e a sua obra}

Quando se fala em Machado de Assis é comum dividir sua obra em duas fases. Na primeira fase os personagens não fazem objeções à sociedade Brasileira, nem possuem grandes ascensões, são mais conformistas. Após a publicação de Memórias Póstumas de Brás Cubas é como se a partir dessa nova obra surgisse um novo escritor, um gênio, ousado e moderno, um homem à frente do seu tempo e de seus contemporâneos. Na visão de Bosi, "compreende-se melhor se atribuída a uma reestruturação original da existência operada pelo homem que, se havia muito perdera as ilusões, ainda não encontrara a forma ficcional de desnudar as próprias criaturas". (BOSI, 2006,p. 176) Isto é, ainda não aprendera o manejo do distanciamento. Porém, alguns temas são recorrentes desde sua primeira fase, tais como: ciúmes, ambição, dinheiro, ascensão social, parasitismo social, criação artística e etc.

Para o pesquisador Álvaro Marins "embora Machado tenha trabalhado poucos temas em toda a sua obra, trabalhou-os de forma bastante articulada, e sua genialidade está muito mais calcada no aprofundamento dos mesmos do que em supostas e discutíveis rupturas estéticas". (MARINS, 2008, p. 12). Em acordo com Marins, se analisarmos bem, não há uma ruptura. A primeira fase, por ser considerada romântica, seria uma obra menor? A escrita machadiana vai amadurecendo ao longo das publicações e assim os temas da chamada segunda fase, na verdade, apresentam-se mais amadurecidos, com outros ângulos e perspectivas. Machado volta ao mesmo tema, mas com ponto de vista diferente. Nesta segunda fase vem também o avanço da epilepsia, ele torna-se o grande Machado e neste quesito passa a pena ao senhor de engenho, aos personagens da alta sociedade. É deste ponto de vista que conhecemos, por exemplo, a história de Dom Casmurro e Memórias póstumas de Brás Cubas. Neste ponto que debruço também com outras lendas que giram em torno da influência de Carolina, sua esposa então, em sua escrita. Até o presente momento da pesquisa eu não encontrei nenhum fato concreto para tal informação. De fato, e isso é possível, que Carolina fora sua primeira leitora e de certo pela formação e vivência da Europa assim o apontasse pontos cruciais nesse processo de criação.

Vale destacar alguns desses temas elencados. Em A mão e a luva, o personagem Estevão é romântico ao estilo de Werther, de Goethe, o que o escritor assume logo com sua fina ironia para apresentação do perfil da personagem. "O rapaz acertara de abrir uma página de Werther, leu meia dúzia de linhas, e o acesso voltou mais forte do nunca" (ASSIS, 2015, p17). Como não observarmos que Felix de Ressureição já é um embrião do protótipo de Bentinho, em Dom Casmurro? Assim, como a inteligência de Guiomar, de A mão e a luva, se assemelha ao caráter de Capitu, também em Dom Casmurro. O tema do ciúme, por exemplo, na percepção de Helen Caldwell "nunca deixou de fascinar Machado de Assis. Em suas obras, seja em artigos ou na ficção, ele frequentemente faz pausas para manipular um lento bisturi sobre uma nova manifestação de ciúme." (CALDWELL, 2002 ,p.18). Ainda é importante frisarmos os narradores dessa segunda fase. A construção dos narradores permite que o escritor volte em alguns temas por outras perspectivas. Em Dom Casmurro, o protagonista Bento Santiago participa da história e só conhecemos toda trama e intriga do seu ponto de vista, ao contrário do narrador de Ressureição que não participa da história. Experimentar narradores para tratar de temas é recorrente na obra machadiana.

A cidade do Rio de Janeiro é um personagem recorrente nas obras do escritor. Como ler Machado sem ler o Rio de Janeiro? Seria como Proust sem Paris. Suas narrativas trazem um roteiro cartográfico das ruas. Machado vive entre o apogeu e a decadência da monarquia. O Rio em sua obra é a capital federal, sendo a única cidade cosmopolita do país até aquele momento. Personagens como Quincas Borba, Conselheiro Aires, Bentinho e Capitu atestam o labirinto não revelado pelas ruas. A musicalidade também se faz presente nos contos, como o tema da perfeição, do inatingível, que gera dúvida e sua eterna insatisfação. Seria uma versão do próprio Machado pelo avesso? Aquele que não foi, o que não deu certo. O que dizer de Mestre Romão, em Cantiga de esponsais, e seu desejo de criar e a falta de linguagem para executar sua realização? Em Um homem célebre, se observa o desejo de compor uma obra clássica. Essa musicalidade também é invocada em vários momentos de Memorial de Aires. Em Esaú e Jacó, a personagem Flora toca ao piano e funde-se em pensamentos com os dois irmãos. Nas palavras de Machado de Assis:

Tudo se mistura à meia claridade; tal seria a causa da fusão dos vultos, que de dous que eram, ficaram sendo um só. Flora, não tendo visto sair nenhum dos gêmeos, mal podia crer que formassem agora uma só pessoa, mas acabou crendo, mormente depois que esta única pessoa solitária parecia completá-la interiormente, melhor que nenhuma das outras em separado (ASSIS, 2015,p.178).

Ou seriam esses personagens uma mistura das aspirações do próprio escritor, que almejava subir na 
vida e atingir sua ascensão social, como atestou Lucia Miguel Pereira (1988)?

\section{Resultados obtidos}

Machado de Assis, de fato, não teve filhos, mas deixou para as novas gerações o legado de sua obra. Não por acaso é considerado o pai da prosa brasileira moderna. Reconstruir os passos desse homem não é a mais simples das tarefas e a cada leitura realizada o quebra cabeça só aumenta, assim como as dúvidas e os conflitos do personagem e do roteirista.

Torna-se importante ressaltar que este é um trabalho em construção e os resultados apresentados estão inseridos até este momento da pesquisa. Dentro do meu cronograma de trabalho, os autores escolhidos para a pesquisa foram: Daniel Piza (2008), Lucia Miguel Pereira (1988) e Alfredo Pujol (2007). Os três autores já lidos e com fichamento de cada livro. Para Pujol (2007), uma das principais características do escritor era a ambição e a obsessão com a arte. O crítico estabelece um diálogo também com Lucia Miguel Pereira (1988), onde diz que timidez, ambição e oralidade caminhavam juntos com Machado. Mas, ao contrário de Lucia Miguel Pereira, ele não aborda a questão da cor de Machado de Assis, e quando assim o faz, aponta de forma simples, com uso de adjetivos, para dizer sobre o universo que habitou. São frases como esta: "Numa pobre habitação" (PUJOL, 2007, p. 53). Pujol utiliza-se da expressão "um homem simples" em diversos momentos. O que mais destacou nesta biografia foram as leituras que Machado realizava de outros autores e isso Pujol resgata magistralmente. Segundo Pujol, Machado era leitor voraz de obras de Stendhal e Shakespeare, "que devia ser mais tarde um dos modelos do seu espirito." (PUJOL, 2007, p. 6). Já a biografia de Danizel Piza (2008) trabalha com Machado de Assis consagrado e, principalmente por ser mais recente, toda sua pesquisa se debruça em cima de outros autores que publicaram biografias de Machado; trata-se, portanto, de uma releitura, mas uma releitura com valor, pelo fato de Piza apresentar um Machado mais solar, o avesso do que o enxergamos. Em Piza, o caráter gregário é risonho. O homem Machado era risonho e integrado ao tempo. Machado está intocável do ponto de vista humano, mas como um homem do seu tempo. Se Lucia Miguel Pereira (1988) analisa a oralidade, Piza analisa as cartas. O aspecto da infância é pouco mapeado pelo autor e o mesmo faz um exercício de metalinguagem onde inicia a biografia pela morte do escritor fazendo uma alusão à obra Memórias Póstumas de Brás Cubas; o foco é o autor-criador e não o personagem Machado. A própria proposta de Piza já traz um distanciamento do personagem quando o mesmo oferta "Machado de Assis: um gênio brasileiro". Se é gênio já pressupõe quase um intocável e talvez por isso o autor não quis se envolver em polêmicas, ao não trabalhar com o abandono da madrasta por Machado, um dos personagens mais marcantes de sua infância.

Outro ponto que considero bastante relevante nesta leitura de Piza é a contextualização, pois o mesmo trabalha o crescimento do autor Machado de Assis com o crescimento do país. Para Piza, as críticas que ocorrem em relação ao apadrinhamento de Machado se devem ao seu talento, mas todo vencedor precisa de um apadrinhamento, alguém precisa descobrir e acreditar e assim fizeram com Machado.

Em relação ao grande escritor que se tornou Machado de Assis, é Alfredo Pujol quem traz uma assertiva o qual concordo inteiramente e encontra-se na fala de Machado: "a natureza não me interessa, o que me interessa é o homem." (PUJOL, 2007, p. 61). Se assim analisarmos, toda obra de Machado é de contexto universal, são personagens com complexidades e camadas inerentes em qualquer cultura.

\section{Resultados esperados}

Ao final da pesquisa, espera-se um material rico de informações e, principalmente, que o argumento escrito com base nesta pesquisa possa resultar, em uma etapa posterior, em um roteiro completo. Machado de Assis, que nos brindou com tantas histórias, merece ter sua própria história retratada na grande tela e por que não o apresentar ao mundo como um brasileiro vencedor. As críticas virão e faz parte do jogo, mas é muito prazeroso poder conviver com tantos personagens machadianos e a minha visão como roteirista se amplia muito neste universo, sem dizer a experiência enriquecedora de construção de personagens que somente um autor como Machado de Assis poderia nos ofertar, e quanto a isso me sinto novamente fazendo um curso a parte. Este projeto até o momento tem sido realizado de forma individual e talvez assim o seja mesmo por ser tão autoral.

\section{Conclusão}

Acredito que o trabalho da pesquisa irá me levar por outros caminhos ainda não percorridos e como criador me deixo guiar sem nenhuma preocupação. O processo em si exige essa liberdade de criação e cada história tem o seu tempo de maturação. Estou com três meses de pesquisa e pretendo ficar mais três meses até começar o processo de escrita do argumento em si. Desde o momento em que rascunhei algumas linhas para o personagem, o olhar com as novas informações que vão surgindo modifica o rumo da história. No processo inicial procurei direcionar apenas na segunda fase de Machado, por uma questão de custo e recorte. No entanto, as leituras das biografias me proporcionaram uma visão mais ampla desta história. Um exemplo é o crescimento do homem Machado de Assis com o crescimento do país. $\mathrm{O}$ aspecto da contextualização é determinante para saber quem foi esse homem, de onde ele veio e o que queria alcançar. Escrevendo desta forma parece um desenho de personagem meticuloso e assumo que o é, pois no decorrer da construção, eu, enquanto roteirista, preciso esquecer o célebre autoral para acreditar no meu personagem. Digo meu personagem pois se trata da minha criação, o meu olhar, a minha visão de mundo sobre esse homem e o recorte que 
escolhi para fazer sua cinebiografia. Cada roteirista trabalha com sua própria visão de mundo e neste aspecto as referências são diferentes, em alguns momentos se encaixam e em outros não, mas o mais importante de tudo é a história a ser contada, como nos ensinou o mestre Machado de Assis.

\section{Bibliografia}

ASSIS, Joaquim Maria Machado. Obras completas. 4 volumes. São Paulo: Editora Nova Aguilar, 2015.

BOSI, Alfredo. História concisa da literatura brasileira. São Paulo: Editora Cultrix, 2006.

CALDWELL, Helen. O Otelo brasileiro de Machado de Assis: um estudo de Dom Casmurro. São Paulo: Ateliê Editorial, 2002.

CAMPOS, Flávio de. Roteiro de cinema e televisão: a arte e a técnica de imaginar, perceber e narrar uma estória. Rio de Janeiro: Ed. Jorge Zahar, 2007.

MARINS, Álvaro (Org.). Páginas esquecidas: uma antologia diferente de contos machadianos. 01. ed. Rio de Janeiro: Língua Geral, 2008.

MASSA, Jean-Michel. A juventude de Machado de Assis. Rio de Janeiro: Civilização Brasileira, 1971.

PEREIRA, Lúcia Miguel. Machado de Assis (Estudo crítico e biográfico). Belo Horizonte / São Paulo: Itatiaia / EDUSP, 1988.

PIZA, Daniel. Machado de Assis. Um gênio brasileiro. São Paulo: Imprensa Oficial, 2005.

PUJOL, Alfredo. Machado de Assis. Rio de Janeiro: Academia Brasileira de Letras, 2007.

ROCHA, João Cesar de Castro. Machado de Assis: por uma poética da emulação. $1^{a}$ ed. Rio de Janeiro: Civilização Brasileira, 2013.

SANTIAGO, Silviano. Machado. São Paulo. Companhia das Letras, 2016

TARKOVSKI, Andrei. Esculpir o tempo. São Paulo: Martins Fontes, 2010.

VOGLER, Christopher. A jornada do escritor: estruturas míticas para escritores. 2. Ed. Rev. E ampliada. Rio de Janeiro: Nova Fronteira, 2006. 